\title{
Nuclear cataract and myopia during hyperbaric oxygen therapy*
}

\author{
BRITT-MARIE PALMQUIST, ${ }^{1}$ BO PHILIPSON, ${ }^{1}$ AND PER-OLOF BARR ${ }^{2}$ \\ From the ${ }^{1}$ Department of Ophthalmology, Karolinska Hospital, and the ${ }^{2}$ Hyperbaric Unit, \\ Rosenlunds Hospital, Stockholm
}

SUMmaRY The effect on the human lens of prolonged hyperbaric oxygen therapy is reported. Eye examinations were given to 25 patients before, during, and after a series of 150 or more exposures to hyperbaric oxygen. All patients changed refraction in the direction of myopia during treatment. Fifteen of the patients had clear lens nuclei before treatment. Seven of these developed a nuclear cataract with reduced visual acuity during treatment. Reversible lens myopia has previously been noticed as a side effect of exposure to hyperbaric oxygen, but the cataractogenic effect in man has not been reported by other workers. This report strongly supports the theory of an oxidative damage to the lens proteins as a cause of nuclear cataract.

Hyperbaric oxygen therapy is of growing interest for the treatment of persistent ulcers due to impaired peripheral circulation. An increase in the partial pressure of the oxygen in the lungs results in an increased uptake of oxygen in the arterial blood in physically dissolved form. This increase in oxygen content of the blood can compensate for the decrease in the blood flow in the ischaemic areas.

Hyperbaric oxygen therapy has been used for many years, but there are only a few reports on its long-term side effects in the human eye. Several toxic effects on the eye have been reported experimentally. Guineapigs exposed to $100 \%$ oxygen at 3 ata (atmospheres absolute pressure) showed thinning of the corneal endothelium and damage to the lens epithelium. ${ }^{1}$ Mice repeatedly exposed to hyperbaric oxygen developed cataract. ${ }^{2}$ In man a constriction of the retinal vessels and narrowing of the visual fields has been shown. ${ }^{3}$ Retrolental fibroplasia is a well-known manifestation of oxygen toxicity in premature infants. ${ }^{4}$ Cicatricial retrolental fibroplasia is regularly accompanied by myopia, and its degree roughly parallels the severity of the cicatricial changes. ${ }^{5}$ In 1977 we presented a report on lens myopia and nuclear cataract following long-term hyperbaric oxygenation. ${ }^{6}$ Reversible lens myopia without

${ }^{*}$ This study was presented in part at the Fourth International
Congress of Eye Research (ISER), New York, 2 October 1980.

Correspondence to Dr B-M. Palmquist, Department of Ophthalmology, Karolinska Hospital, S-104 01 Stockholm, Sweden. cataract has been reported by Lyne ${ }^{7}$ and by Anderson and Farmer. ${ }^{8}$

In this study the effect of a prolonged series of hyperbaric oxygen treatments on the human lens is reported.

\section{Material and methods}

In a series of patients accepted for hyperbaric oxygen treatment of persistent leg ulcers (Rosenlunds Hospital, P.O. Barr) those patients expected to need prolonged treatment were referred for ophthalmological examination. Of these, 25 cases were treated for 150 hours or more and were examined before, during, and after treatment. Most patients suffered from peripheral ischaemic ulcers of arteriosclerotic origin. Five of the patients were diabetic. The total number of treatments varied from 150 to 850 exposures during 2 to 19 months (one exposure $=$ one hour). Daily treatments were given 7 days a week with pure oxygen for $2 \times 1$ hours at $2-2.5$ times normal atmospheric pressure. Vickers monoplace acrylic plastic chambers (Vickers Ltd, Hampshire, England) were used. The full hyperbaric pressure was maintained for 50 minutes during every treatment. The pressure was raised during 10 minutes and reduced during half that time. Additional therapy during the hyperbaric oxygen treatment consisted of vitamin $E$ (Ephynal) $0.3 \mathrm{~g} \times 3$, as a prophylactic against oxygen toxicity effects, zinc sulphate, $0.2 \mathrm{~g} \times 2$, in case of zinc deficiency, and antibiotics if the ulcers were severely 
Table 1 The age and sex distribution of treated and untreated groups

\begin{tabular}{lll}
\hline & Treated & Untreated \\
\hline Number of patients & 25 & 19 \\
Age distribution (mean $\pm \mathrm{SD})$ & $65 \cdot 5 \pm 15 \cdot 9$ & $69 \cdot 1 \pm 11 \cdot 75$ \\
$\begin{array}{l}\text { Sex distribution } \\
(\mathrm{M}=\text { male, } \mathrm{F}=\text { female })\end{array}$ & $14 \mathrm{M} \quad 11 \mathrm{~F}$ & $9 \mathrm{M} 8 \mathrm{~F}$ \\
\hline
\end{tabular}

infected. Two patients were treated with corticosteroids.

During the study the eyes were examined after each 100 treatments (approximately 2 months) by one of the 2 ophthalmologists (B-M.P. and B.P.). The corrected visual acuity tested by Monoyer's chart and the refraction by Donders's subjective method were recorded. Distance and illumination were the same during the whole study. The pupils were dilated with Mydriacyl alone or in combination with Neosynephrine $10 \%$ if needed.

The biomicroscopic appearance of the lens was examined with a Haag-Streit 900 slit-lamp microscope. Photographic records with a Nikon photo slitlamp were made initially and whenever lens changes were found. The central fundus was also inspected. In a few cases when the 2 eyes of a patient were unequally affected the eye with the largest refractive change after 100 hours of treatment was selected for further comparisons and analysis.

Nineteen patients on the waiting list for hyperbaric oxygen treatment were selected as a reference group. These where comparable to the oxygen-treated group in most aspects except for the age distribution (Table 1 ). The mean age for the treated group was 65.5 years and for the reference group $69 \cdot 1$. This was explained by the fact that younger patients had a relative

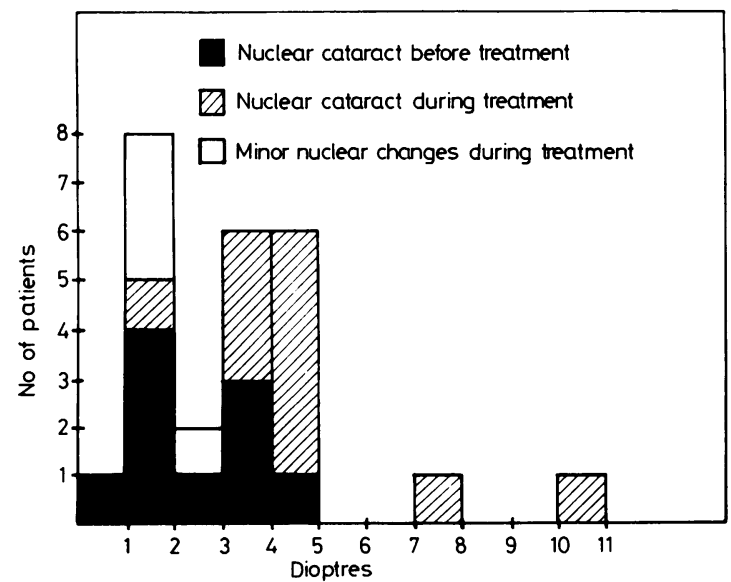

Fig. 1 The maximal refractive change in the myopic direction of the 25 patients. Patients developing a nuclear cataract also show the greatest myopic change. priority for treatment. The reference group did not get any oxygen treatment during the examination period of 12 months.

Nuclear cataract is defined as an increased turbidity in the lens nucleus to such an extent that it appears equal to or more opaque than the cortex when seen in the slit-lamp. Generally it then causes some reduction of visual acuity. Nuclear turbidity (cataract) was graded from $1+$ to $4+$, where $1+$ corresponded to an increased light scattering in the nucleus equal to the inner cortical region and $4+$ to a totally opaque nucleus.

A yellow-brown colouration was not considered to represent cataract. Grading of the nuclear colour was made from $1+$ to $4+$, where $1+$ corresponded to pale yellow and $4+$ to brown or darker.

Data on the development of cataract in the treated and untreated groups of patients were statistically analysed by Fisher's exact test (one-sided).

\section{Results}

\section{MYOPIA}

In all but one of the 25 patients studied the refraction changed in the direction of myopia by 1 dioptre or more during the oxygen treatment. Both eyes were equally affected, with only a few exceptions. In 23 of 25 patients myopia was noted after 100 treatment hours. The mean value of all patients' maximal change in refraction was 3.0 dioptres (Fig. 1). This maximal change occurred between 100 and 300 treatment hours in 24 patients. In one patient the maximum occurred after 500 treatment hours. The large variation in maximal refractive change was not age related. Of the 18 patients over 60 years of age 9 had clear lens nuclei and 9 had nuclear cataract before treatment. The patients with clear lens nuclei before treatment developed a significantly $(\mathrm{p}<0.05)$ higher grade of myopic change $(4 \cdot 2 \pm 2 \cdot 3$ dioptres) than the patients with a nuclear cataract before treatment $(2 \cdot 1 \pm 1 \cdot 3$ dioptres). In most of the cases with extended treatment programmes the myopia started to reverse during therapy. In 11 patients myopia was persistent for at least 6 months after termination of oxygen therapy. The remaining myopic change was 1 dioptre or more.

The mean value of the maximal change in refraction was the same for the diabetic patients as for the whole group ( $3 \cdot 1$ dioptres).

No one in the reference group showed a myopic change in refraction of 1 dioptre or more during the follow-up time of 1 year.

CATARACT

Fifteen of the 25 oxygen treated patients had clear lens nuclei before treatment. In 7 of these a nuclear 


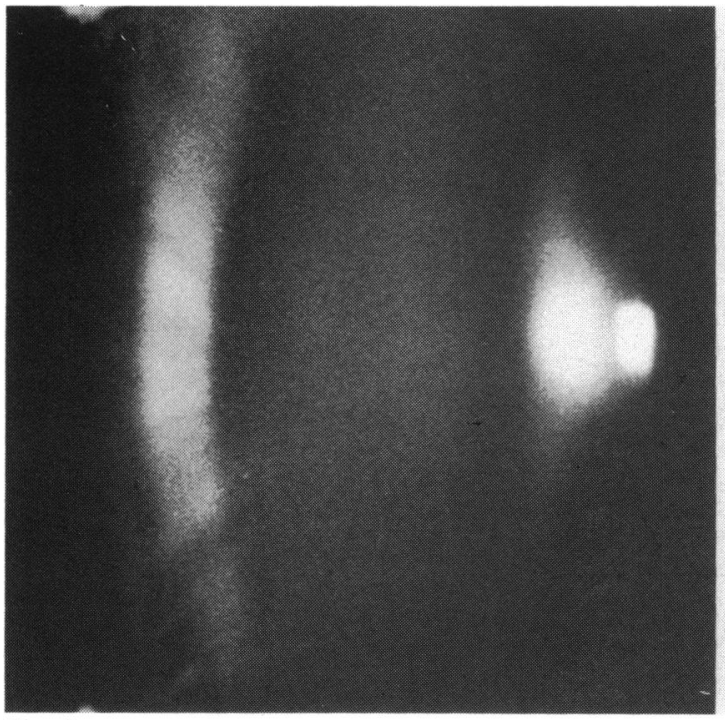

Fig. 2a

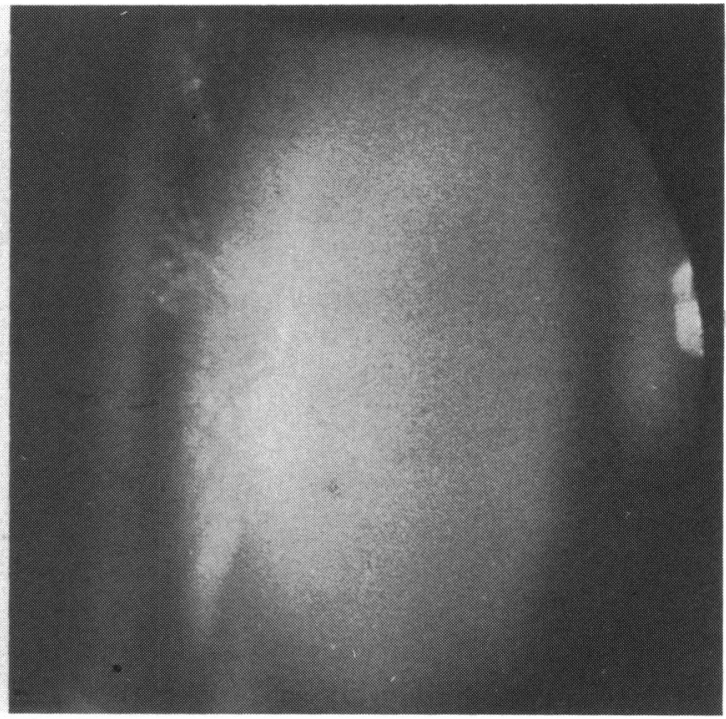

Fig. $2 b$

Fig. 2 Appearance of the lens in a 79-year-old male (a) before treatment and (b) after 8 months of treatment. Note the increased turbidity of the lens nucleus. Visual acuity was $1 \cdot 0(6 / 6)$ and $0 \cdot 7(6 / 9)$ respectively.

cataract with a definite increase of the grey turbidity in the nucleus and with a reduced visual acuity of $0 \cdot 3$ or more developed during treatment (Fig. 2). In addition in all but one of these lenses an increasing yellow-brown colour was seen. The increase in yellowing and turbidity of the nucleus were not always parallel and were therefore recorded separately (Table 2). In 4 of the 7 patients the cataract and the reduction of visual acuity developed within 6 months of treatment and in the other 3 within a year. Mean reduction of visual acuity was $0 \cdot 5$. In 2 patients (nos. 12 and 14 in Table 2) the lens changes were partly reversible. After termination of oxygen therapy their visual acuity improved and the simultaneous myopia was reduced (Fig. 3). However, the lens nucleus never became normal.

In 7 of the remaining 8 subjects an increased nuclear light-scattering was seen, though without a significant effect on the visual acuity. The youngest patient, only 23 years of age, did not develop any lens changes.

Twelve of the 19 patients in the reference group

Table 2 Relationship between treatment duration in patients with clear lens nuclei before start of treatment and changes in visual acuity, refraction, and lens parameters

\begin{tabular}{|c|c|c|c|c|c|c|c|c|c|c|c|}
\hline \multirow[t]{2}{*}{ Patient } & \multirow[t]{2}{*}{ Age } & \multicolumn{2}{|c|}{ Treatment } & \multicolumn{2}{|c|}{ Visual acuity } & \multicolumn{2}{|c|}{$\begin{array}{l}\text { Refractive change } \\
\text { (dioptres) }\end{array}$} & \multicolumn{2}{|c|}{ Turbidity } & \multicolumn{2}{|l|}{ Colour } \\
\hline & & Hours & Months & Before & After & $\operatorname{Max}$ & After & Before & After & Before & After \\
\hline 1 & .45 & 150 & 4 & $1 \cdot 0$ & $1 \cdot 0$ & $-2 \cdot 0$ & $-2 \cdot 0$ & - & + & - & - \\
\hline 2 & 23 & 160 & 4 & $1 \cdot 0$ & $1 \cdot 0$ & $-1 \cdot 0$ & $-1 \cdot 0$ & - & - & - & - \\
\hline 3 & 44 & 190 & 4 & $1 \cdot 0$ & $1 \cdot 0$ & $-1 \cdot 75$ & $-1 \cdot 25$ & - & + & - & - \\
\hline 4 & 53 & 200 & 5 & $1 \cdot 0$ & 0.6 & $-7 \cdot 0$ & $-7 \cdot 0$ & - & ++ & - & - \\
\hline 5 & 46 & 230 & 8 & $1 \cdot 0$ & $1 \cdot 0$ & $-1 \cdot 25$ & $-1 \cdot 25$ & - & + & - & - \\
\hline 6 & 68 & 300 & 12 & $1 \cdot 0$ & 0.9 & $-1 \cdot 5$ & $-1 \cdot 0$ & - & + & - & ++ \\
\hline 7 & 74 & 335 & 9 & $1 \cdot 0$ & 0.6 & $-4 \cdot 0$ & $-2 \cdot 0$ & - & + & + & ++ \\
\hline 8 & 79 & 400 & 11 & $1 \cdot 0$ & 0.6 & $-3 \cdot 0$ & $-1 \cdot 0$ & - & ++ & + & +++ \\
\hline 9 & 70 & 510 & 18 & $1 \cdot 0$ & $0 \cdot 8$ & $-3 \cdot 25$ & $-2 \cdot 75$ & - & ++ & + & ++ \\
\hline 10 & 62 & 540 & 19 & $1 \cdot 0$ & $0 \cdot 3$ & $-10 \cdot 0$ & $-6 \cdot 0$ & - & ++ & - & ++ \\
\hline 11 & 62 & 600 & 18 & $1 \cdot 0$ & 0.5 & $-4 \cdot 5$ & $-4 \cdot 5$ & - & ++ & + & ++ \\
\hline 12 & 72 & 600 & 13 & $1 \cdot 0$ & 0.7 & $-3 \cdot 5$ & $-1 \cdot 25$ & - & + & - & ++ \\
\hline 13 & 56 & 630 & 16 & $1 \cdot 0$ & 0.9 & $-4 \cdot 0$ & -0.5 & - & ++ & + & ++++ \\
\hline 14 & 60 & 700 & 17 & $1 \cdot 0$ & $0 \cdot 3$ & $-3 \cdot 5$ & $-3 \cdot 5$ & - & ++ & - & ++ \\
\hline 15 & 60 & 850 & 17 & 0.9 & 0.7 & $-4 \cdot 5$ & $-2 \cdot 5$ & - & ++ & + & ++ \\
\hline
\end{tabular}


Fig. 3 The change in visual acuity and refraction during oxygen treatment in a 72-year-old male (no. 12, Table 2). The patient developed a partly reversible nuclear cataract. In the treatment schedule each line indicates 10 hours of treatment. Visual acuity 1.0 and 0.5 corresponds to $6 / 6$ and $6 / 12$ respectively.

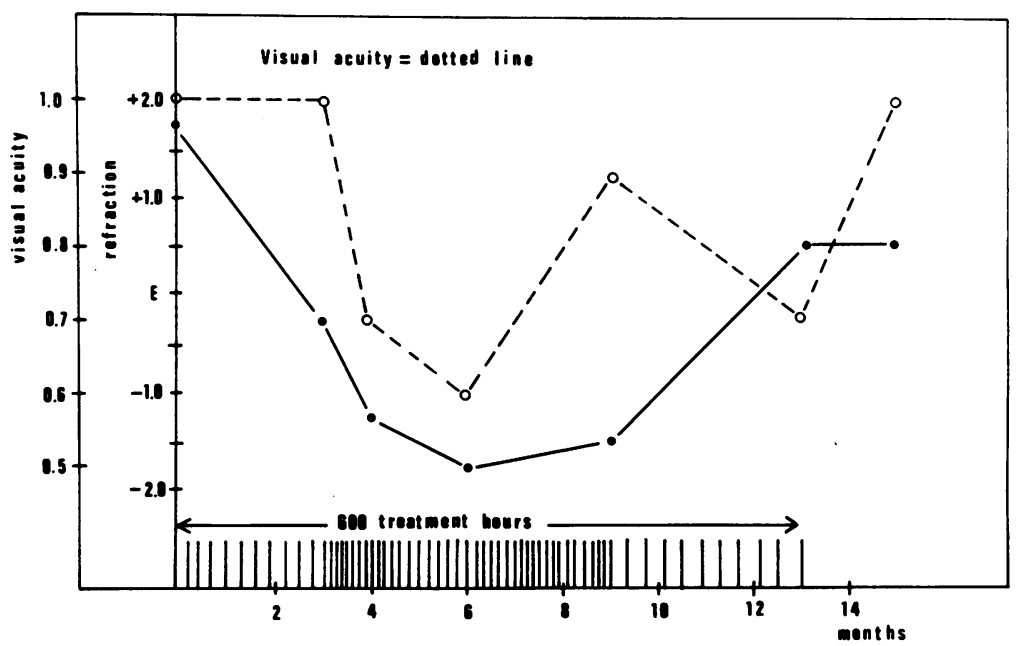

change in refraction seen by us after about 200 treatment hours might be explained by some sort of reparative process taking place in the lens itself. The refractive change is considered to be due entirely to changes in the lens, as no changes in the cornea or axial length of the eye have been found..$^{78}$

We consider the myopic change to be a sign of increasing nuclear cataract. The relationship between increasing myopia and senile nuclear cataract is well known. Among the oxygen treated patients over 60 years of age there was an inverse correlation between the degree of myopic change and the degree of pretreatment nuclear cataract. This can be explained by the much greater possibility for the clear lens nucleus to develop an increasing myopia, together with an increasing nuclear cataract.

The cataractogenic effect of hyperbaric oxygen in man has not been reported by others. This is explained by the uniquely prolonged and intensive treatment program used on our patients, in which 14 were treated between 300 and 850 hours. In general,

Table 3 Comparison between the treated and untreated groups of patients

\begin{tabular}{|c|c|c|}
\hline & Treated & Untreated \\
\hline $\begin{array}{l}\text { Patients with clear lens nuclei } \\
\text { at first examination }\end{array}$ & $15(60 \%)$ & $12(63 \%)$ \\
\hline $\begin{array}{l}\text { Age distribution (mean } \pm S D \text { ) } \\
\text { Sex distribution }\end{array}$ & $58 \cdot 3 \pm 14 \cdot 4$ & $65 \cdot 4 \pm 11 \cdot 9$ \\
\hline $\begin{array}{l}(\mathrm{M}=\text { male }, \mathrm{F}=\text { female }) \\
\text { Nuclear cataract formation with }\end{array}$ & $11 \mathrm{M} \quad 4 \mathrm{~F}$ & $8 \mathrm{M} \quad 4 \mathrm{~F}$ \\
\hline $\begin{array}{l}\text { visual impairment of } 0.3 \text { or more } \\
\text { within a year* }\end{array}$ & 7 & 0 \\
\hline $\begin{array}{l}\text { Myopic refractive change of } 1 \\
\text { dioptre or more }\end{array}$ & 15 & 0 \\
\hline
\end{tabular}

* Corresponding approximately to a decrease in visual acuity from $6 / 6$ to $6 / 9$. 
patients developing nuclear cataract with visual impairment were subjected to more extensive treatment than those who did not. It could be objected that the definition and grading of the nuclear cataract was subjective. However, the results were supported by the registered visual acuity and refraction. The increasing myopia and the decreasing (best corrected) visual acuity both paralleled the increasing nuclear cataract.

Seven out of 15 patients with clear lens nuclei developed a nuclear cataract with visual impairment, 4 within 6 months and 3 within a year. This incidence $(47 \%)$ of nuclear cataract with visual impairment is extremely high. Our reference group consisted of patients on the waiting-list for hyperbaric oxygen treatment and could be considered equal to the treated group according to state of primary illness. The difference between the 2 groups (Table 3 ) in development of nuclear cataract and myopia is marked and significant. Consequently, the rapid development of nuclear cataract in the treated group can by no means be explained by the normal incidence of senile nuclear cataract.

The partly reversible nuclear cataract observed in 2 patients has not been reported previously. So far nuclear cataract in humans has been considered to be irreversible, but apparently the lens can sometimes recover from an acute toxic event of this kind. The myopia seems to be a very early sign of the toxic damage to the lens, while the nuclear cataract is probably a sign of a more definite damage, much harder to repair. In young patients with short treatments an increase in turbidity, but not in colour, was found. In patients with long treatments both turbidity and colour increased.

Apparently the turbidity is affected primarily and the colour secondarily. The increase in colour may be a function of age only. A widely accepted theory on the development of nuclear cataract suggests an oxidative damage to the lens proteins causing the formation of large and dense molecular aggregates. ${ }^{-11}$ Each aggregate will scatter light and if present in sufficiently high concentration results in lens opacity. ${ }^{12}$ Possible oxidative agents include oxygen, which is known to be toxic to most tissues in excessive amounts. The toxicity is mediated through the oxidising free radicals. Several defence systems against these radicals are found in the lens. The most important is the glutathione system. Lack of protective agents against the oxidising free radicals or excessive amounts of oxidising radicals could theoretically be cataractogenic.

The rapid development of nuclear cataract in patients under hyperbaric oxygen treatment strongly supports the oxidative theory of nuclear cataract formation.

The obvious cataractogenic effect of hyperbaric oxygen treatment should be considered before starting therapy. The patient must be informed and the treatment period must be kept as short as possible.

This investigation was supported by grants from the Swedish Medical Research Council (12X-4204), Carmen and Bertil Regnér's Foundation for Eye Research, and from the Karolinska Institute, Stockholm.

\section{References}

1 Nichols CW, Yanoff M, Hall DA, Lambertsen CJ. Histologic alterations produced in the eye by oxygen at high pressure. Arch Ophthalmol 1972; 87: 417-21.

2 Schocket SS, Esterson J, Bradford B, Michaelis M, Richards RD. Induction of cataracts in mice by exposure to oxygen. Isr J Med Sci 1972; 8: 1596-601.

3 Nichols CW, Lambertsen CJ. Effects of high oxygen pressures on the eye. N Engl J Med 1969; 281: 25-30.

4 Kinsey VE. Retrolental fibroplasia: cooperative study of retrolental fibroplasia and the use of oxygen. Arch Ophthalmol 1956; 56: 481-529.

5 Fletcher MC, Brandon S. Myopia of prematurity. Am J Ophthalmol 1955; 40: 474-81.

6 Palmquist BM, Barr PO, Fagerholm PP, Philipson BT. Lens myopia and nuclear cataract induced by hyperbaric oxygen therapy. Transactions of the Swedish Ophthalmological Society 1977. Acta Ophthalmol (Kbh) 1978; 56: 476.

7 Lyne AJ. Ocular effects of hyperbaric oxygen. Trans Ophthalmol Soc UK 1978; 98: 66-8.

8 Anderson B, Farmer JC. Hyperoxic myopia. Trans Am Ophthalmol Soc 1978; 76: 116-24.

9 Spector A. Aggregation of $\alpha$-crystallin and its possible relationship to cataract formation. Isr J Med Sci 1972; 8: 1577-82.

10 Spector A, Garner MH, Roy D, Garner WH, Farnsworth PN, Shyne S. Oxidation of lens proteins. In: Srivastava SK, ed. Red blood cell and lens metabolism. New York: Elsevier. North Holland, 1980: 81-93.

11 Spector A, Garner MH. Interaction of human cataract fiber cell membrane polypeptides with cytoplasmic components. In: Srivastava SK, ed. Red blood cell and lens metabolism. New York: Elsevier North Holland, 1980: 233-236.

12 Benedek GB. Theory of transparency of the eye. Appl Optics 1971; 10: 459-73. 